\title{
FaceEduc: Análises e Resultados da Adaptação Gráfica do Moodle baseada no Facebook
}

\author{
Gliner Dias Alencar ${ }^{1}$, Juliana Ferreira G. da Silva ${ }^{1}$, Lígia Maria S. Passos ${ }^{2}$, Cecir \\ Barbosa A. Farias ${ }^{3}$, Anderson Apolonio L. Queiroz ${ }^{1}$ \\ ${ }^{1}$ Universidade Federal de Pernambuco - Recife - Pernambuco - Brasil \\ ${ }^{2}$ Universidade Federal Rural do Rio de Janeiro - Nova Iguaçu - Rio de Janeiro - Brasil \\ ${ }^{3}$ Universidade Federal de Campina Grande - Sumé - Paraíba - Brasil \\ \{gda2, aalq\}@cin.ufpe.br, julianafgs@yahoo.com.br, \\ ligiamaria.soarespassosegmail.com, calmeida@ufcg.edu.br
}

\begin{abstract}
This paper presents the experience of FaceEduc, a graphic adaptation of Moodle based on Facebook. This adaptation includes on Moodle's environment the features of a social network as a way of interaction among students, teachers and other users. To test the performance and acceptance of it, the FaceEduc was tested in Administration and Informatics courses for two consecutive semesters. It leads the visualization of significant improvements in e-learning in several areas, especially in the engagement and motivation of the e-learning students.
\end{abstract}

Resumo. Este artigo relata a experiência do FaceEduc, uma adaptação gráfica do Moodle baseada no Facebook. Tal adaptação inclui ao ambiente as funcionalidades de uma rede social como forma de interação entre os alunos, professores e demais usuários. Para testar a aceitação e desempenho do mesmo, o FaceEduc foi testado em cursos das áreas de Administração e Informática durante dois semestres, o que levou à visualização de melhorias significativas, principalmente no engajamento e motivação dos alunos da modalidade de Educação a Distância.

\section{Introdução}

O sistema educacional brasileiro tem sofrido consideráveis mudanças desde que, na década de 90, com o avanço da tecnologia e, principalmente, devido ao alcance da Internet pela população, a inclusão de softwares educacionais como ferramenta de auxílio à aprendizagem dos alunos criou uma nova modalidade no processo de ensinoaprendizagem, a chamada Educação a Distância (EaD). Para apoiar a citada modalidade, são utilizados ambientes computacionais denominados Ambientes Virtuais de Aprendizagem (AVAs). Estes ambientes suportam o processo de comunicação entre alunos, professores e instituição de ensino fazendo com que todos participem de modo interativo, tanto no meio acadêmico quanto no corporativo, como corroboram Oliveira et al (2010). Mesmo com a crescente utilização, os AVAs e a própria modalidade EaD ainda carecem de melhorias significativas em diversas áreas. Entre elas, podemos citar os diversos problemas existentes para cativar e motivar os alunos na utilização dos AVAs e, consequentemente, obter uma possível redução da evasão. 
A Web 2.0 caracteriza o lado mais interativo e social da Internet, onde os utilizadores têm um papel preponderante no acesso, difusão e produção das informações e, consequentemente, na sua capacidade e velocidade na geração de conhecimento, visto que as tecnologias inerentes desta nova web (podcasts, wikis, redes sociais, entre outros) fazem parte do cotidiano dos discentes. Neste cenário, o uso de serviços e ferramentas de conectividade garantem acesso rápido, fácil, e na maioria das vezes, seguro aos dados. A Internet, por exemplo, tornou-se o meio de comunicação por excelência, favorecendo a disseminação de conhecimentos e as mais diversas trocas. Sendo assim, cada vez mais pesquisas visam fortalecer a relação pedagógica entre ambos através de tecnologias e ferramentas web que fortaleçam esta interação. Esta nova conjectura, uma sociedade global em rede, afeta a todos, sendo cada usuário um nó desta vasta teia de informações, como citam Castells (2007) e Lévy (1999).

Neste contexto, surgiu o FaceEduc, que, de acordo com Alencar et al (2013), é uma adaptação visual da plataforma de aprendizagem Moodle $^{1}$, baseada na interface e mecanismos de interação da rede social Facebook ${ }^{2}$. Alencar et al (2013) mostram que os alunos se adaptam melhor às tecnologias quando estas vão de encontro aos seus interesses e necessidades pessoais. Ou seja, a utilização do FaceEduc como ambiente de aprendizagem contribuiu para que esse ambiente de aprendizagem fosse gradualmente organizando-se como um espaço de integração, partilha, comunicação e colaboração entre todos os envolvidos, favorecendo e melhorando o desempenho dos discentes. Considerando tais resultados positivos, que a ferramenta continua sendo utilizada como AVA e que amostras de dados mais representativas sobre a utilização da mesma foram coletadas durante dois semestres letivos consecutivos, o presente artigo tem por objetivo mostrar os resultados das análises efetuadas sobre tal amostragem.

\section{Os Ambientes de Redes Sociais}

Com o auxílio da Internet e os avanços tecnológicos nas áreas da comunicação, essas redes puderam ocupar também o ambiente virtual, construindo comunidades virtuais, onde as pessoas podem trocar informações, tornarem-se cada vez mais próximas, compartilhando interesses independentemente de espaço e tempo. Neste contexto, e apoiado pela disseminação de dispositivos móveis, qualquer comentário pode ser visualizado por outros sem distinção de espaço geográfico ou tempo.

Lima et al (2012) citam que o aumento da popularidade dos dispositivos móveis com acesso à Internet e o uso crescente das redes sociais têm contribuído para o surgimento de novos aplicativos que atendem às diversas necessidades dos usuários. As redes sociais vêm ajudando as pessoas a lidar com seus problemas diários, uma vez que facilitam a troca e o compartilhamento de informações dinâmicas, em tempo real, relacionadas aos mais diversos aspectos do cotidiano. Entre as principais redes sociais modernas podemos citar: Facebook, LinkedIn ${ }^{3}$, MySpace $^{4}$ e Orkut ${ }^{5}$. Esta nova ideia de comunidade deve ser mais baseada na cooperação e trocas de recursos que na

\footnotetext{
${ }^{1}$ Moodle - http://moodle.org

${ }^{2}$ Facebook - http://www.facebook.com

${ }^{3}$ LinkedIn - http://www.linkedin.com

${ }^{4}$ MySpace - https://myspace.com

${ }^{5}$ Orkut - http://orkut.com
} 
permanência de laços, descartando os conceitos tradicionais anteriores, onde a proximidade física era fator determinante e limitante para a formação de uma comunidade, como cita Costa (2005).

\subsection{O Facebook}

Atualmente, de acordo com a Alexa (2013), o Facebook é a maior rede social e um dos sites mais visitados do mundo, com 1 bilhão de usuários ativos, ocupando a liderança em 92,7\% dos países analisados por Cosenza (2012) e tem como missão dar às pessoas o poder de compartilhar informações e fazer do mundo um lugar mais aberto e conectado, segundo Facebook (2014). Estes dados e a importância da rede também são citados por Malheiros e Lima (2013). Juntas, as pessoas publicam 7 petabytes de fotos por mês, curtem diariamente mais de 2,7 bilhões de comentários ou postagens, segundo dados da Royal Pingdom (2013). No Brasil, esta rede teve o maior crescimento absoluto de usuários em 2012, e mais de 10 milhões de pessoas aderiram à rede nos últimos 6 meses, conforme Social Barkers (2013). Neste mesmo ano, de acordo com uma pesquisa do Instituto Brasileiro de Opinião Pública e Estatística - IBOPE (2012), o Brasil atingiu o marco de mais de 94 milhões de usuários na Internet.

A facilidade de comunicação e interação entre os usuários desta rede é um dos principais fatores para seu sucesso e elevado grau de aceitação. As pessoas podem postar comentários, compartilhar informações, fotos, vídeos, promover seus blogs pessoais e "curtir" as atividades de seu círculo de amizades. Mendes, Carvalho e Brito (2012) defendem que as redes sociais são como a moda dos tempos modernos para se manter relações e ficar a par das novidades de todos os âmbitos. O Facebook trouxe uma nova forma de comunicação entre as marcas e clientes, proporcionando uma maior aproximação entre ambos, o que pode ocasionar um melhor atendimento e fidelização à marca, pensamento que pode ser facilmente associado não apenas às marcas e ao consumo de produtos, mas também à educação e utilização maciça do AVA, como citam Marcon, Machado e Carvalho (2012) e Ellison, Steinfield e Lampe (2007) no estudo sobre a influência do Facebook na educação.

Com a grande aceitação mundial do Facebook, como já colocado, viu-se uma grande possibilidade de utilização deste meio na educação, de forma a deixá-la mais dinâmica e atrativa. Desta forma, um conjunto de trabalhos acadêmicos tem focado na junção desta rede social com os processos educacionais, sejam interagindo com o Facebook ou fazendo adaptações, como no caso deste trabalho.

Dentre os trabalhos acadêmicos neste sentido, podemos citar Ellison, Steinfield e Lampe (2007) que analisaram a relação entre o uso do Facebook com a formação e manutenção do capital social com estudantes de graduação Universidade do Estado de Michigan (EUA). Marcon, Machado e Carvalho (2012) que conclui em seu estudo que o Facebook pode ser considerado uma arquitetura pedagógica desde que a mediação pedagógica seja intensa, guiada, principalmente, pelo docente com objetivos definidos para ou com o grupo. Já Braz et al (2013) apresentam uma arquitetura flexível para integrar o ambiente Moodle a diferentes sites de redes sociais, inclusive implementando tal solução para integração do Moodle com Facebook e Twitter acreditando que esta integração aumentará a chance de interação entre professor e alunos, além de incentivar os estudantes a serem mais ativos no ambiente. 


\section{Principais AVAs Baseados em Softwares Livres}

Em um contexto geral, a necessidade de expansão dos cursos técnicos e superiores excede a demanda oferecida. Além disso, as necessidades dos discentes se modificaram como o tempo, não tendo, muitas vezes, o tempo necessário para o ensino presencial, conforme Oliveira et al (2010). Assim, a utilização da EaD, com seus AVAs, possibilita o aumento das vagas e diversificação geográfica dos polos de apoio presenciais.

A literatura da área aborda, mais frequentemente, além do Moodle (utilizada neste projeto), mais sete plataformas principais para $\mathrm{EaD}$ baseadas em software livre, não havendo mudanças drásticas de levantamentos anteriores como as pesquisas de Araújo, Cavalcanti e Dos Anjos (2006) e Benício (2005). Estas oito plataformas são sucintamente descritas por Araújo, Cavalvanti e Dos Anjos (2006) conforme Quadro 1.

Quadro 1. Principais Plataformas para EaD baseadas em softwares livres

\begin{tabular}{|l|l|}
\hline Plataforma & \multicolumn{1}{|c|}{ Descrição } \\
\hline ATutor $^{\mathbf{6}}$ & $\begin{array}{l}\text { focando usabilidade e acessibilidade, é de fácil instalação, utilização e } \\
\text { redistribuição de conteúdo pelos educadores. Esta plataforma adota a especificação } \\
\text { IMS/ SCORM para construção de objetos de aprendizagem }\end{array}$ \\
\hline Bodington $^{7}$ & $\begin{array}{l}\text { desenvolvido pelo projeto Bodington, que existe para prover um ambiente que } \\
\text { suporte aprender, lecionar e pesquisar. Esta plataforma é indicada para grandes } \\
\text { organizações complexas e multidisciplinares e para colaboração entre instituições. }\end{array}$ \\
\hline Claroline $^{8}$ & $\begin{array}{l}\text { desenvolvido por pesquisadores professores, permite grande variedade de } \\
\text { estruturações pedagógicas, desde extensões das salas de aula até aprendizado } \\
\text { colaborativo. Esta plataforma é usada em centenas de instituições. }\end{array}$ \\
\hline Moodle $^{1}$ & $\begin{array}{l}\text { baseado na pedagogia do construtivismo, contempla funcionalidades como fóruns, } \\
\text { chats, glossários, pesquisas de opinião, wiki, além de ser compatível com o padrão } \\
\text { SCORM. Está sendo muito difundido por universidades brasileiras. }\end{array}$ \\
\hline Fle3 $^{\mathbf{9}}$ & $\begin{array}{l}\text { sigla de Future Learning Environment, é um software servidor para aprendizado } \\
\text { colaborativo por computador, distribuído sob licença GNU e com versões para } \\
\text { diversos sistemas operacionais. }\end{array}$ \\
\hline Ilias $^{\mathbf{1 0}}$ & $\begin{array}{l}\text { primeiro software livre que alcançou o nível LMS-RT3 de conformidade com o } \\
\text { padrão SCORM 1.2. Esta plataforma contempla e-mail interno, fóruns, chat, } \\
\text { grupos de trabalho e compartilhamento de arquivos. }\end{array}$ \\
\hline LON- $^{11}$ & $\begin{array}{l}\text { Ambiente que contém um repositório de mais de 150.000 itens compartilhados } \\
\text { entre 70 instituições, incluindo questões de avaliações e conteúdo multimídia de } \\
\text { física, química, biologia, matemática, estatística e geologia. }\end{array}$ \\
\hline .LRN $^{\mathbf{1 2}}$ & $\begin{array}{l}\text { baseado em software livre, com código-fonte aberto e originalmente desenvolvido } \\
\text { pelo MIT. Seus recursos incluem e-mail de grupo, calendário, módulos de } \\
\text { avaliação, weblogs, web powerpoint e repositório de objetos de aprendizagem. }\end{array}$ \\
\hline
\end{tabular}

\footnotetext{
${ }^{6}$ ATutor - http://www.atutor.ca

${ }^{7}$ Bodington - http://bodington.org/index.php

${ }^{8}$ Claroline - http://www.claroline.net/

${ }^{9}$ Fle3 - http://fle3.uiah.fi/

${ }^{10}$ ILIAS - http://www.ilias.de/ios/index-e.html

${ }^{11}$ LON-CAPA - http://www.lon-capa.org

12 .LRN - http://dotlrn.org
} 


\section{Metodologia}

Este trabalho quanti-qualitativo, além da pesquisa bibliográfica para formatação de seu referencial teórico, apresenta análises e dados coletados a partir de pesquisa de campo (questionário e coleta de dados) junto com os alunos e equipe educacional da instituição de ensino de nível superior e técnico (IES), na qual ocorreu a proposta de adequação gráfica do Moodle nos moldes do Facebook durante dois semestres letivos do ano de 2013 (2013.1 e 2013.2).

A escolha do AVA Moodle deu-se pelo fato da instituição de ensino financiadora do projeto já utilizar a plataforma supracitada e não demonstrar interesse em alterá-la, mas nada impede que a concepção deste projeto seja adequada às demais plataformas existentes. Já o ambiente de rede social a ser escolhido como base da nova identidade visual, neste caso o Facebook, deu-se pelo sucesso e representatividade desta mídia, o que se acreditava ser um fator positivo para o projeto, pois grande parte dos usuários do AVA já estariam habituados com a nova interface e suas funcionalidades.

Após o desenvolvimento do módulo gráfico FaceEduc, de forma que o Moodle fosse adaptado para utilizar uma interface gráfica semelhante à do Facebook, foi selecionado um conjunto de seis disciplinas de cursos técnicos e superiores nas áreas de Administração e Informática em 2013.1 e adicionadas, às seis, mais quatro disciplinas em 2013.2 (totalizando 6 disciplinas em 2013.1 e 10 em 2013.2 para o referido texto), tendo 1175 alunos participantes (382 em 2013.1 e 793 em 2013.2, os 382 alunos já inseridos em 2013.1 mais 411 adicionados em 2013.2) para experimentar a nova interface e comparar com a plataforma padrão do Moodle, assim como propor melhorias ao projeto.

Todos os alunos encontravam-se matriculados em disciplinas incorporadas ao FaceEduc e outras no ambiente Moodle tradicional, ou seja, estavam interagindo simultaneamente os dois ambientes. Neste contexto, dados sobre o uso do AVA adaptado eram coletados (consumo de recursos da infraestrutura, quantidade e tempo de acesso dos alunos, etc). Complementando a coleta de dados, foi utilizado um questionário para verificar a aceitação e visão dos alunos usuários.

Salienta-se que o presente trabalho não pretende analisar e comparar, neste momento, a usabilidade da interface proposta, mas sim apresentar a utilização da interface, semelhante a de uma mídia social reconhecidamente aceita de forma a deixar o ambiente mais intuitivo para os alunos, visto que grande parte dos mesmos já utiliza o Facebook, e cativá-los com o intuito de evitar a evasão.

\section{O FaceEduc}

O FaceEduc (Figura 1) consiste em um módulo gráfico adaptado ao AVA Moodle (testado e homologado para a versão 2.4) de forma que a sua identidade visual básica fosse parecida com a versão atual do Facebook, uma vez que, por mais que a plataforma Moodle tradicional possibilite alterações e adaptações, ainda é algo diferente do cotidiano dos alunos.

Alguns estudos, por exemplo, Marcon, Machado e Carvalho (2012), já apontaram para a utilização do próprio Facebook como plataforma. Porém, essa hipótese foi descartada para esta pesquisa pelo fato da utilização do próprio Facebook 
não permitir à instituição de ensino o acesso e controle aos perfis dos discentes e demais usuários, assim como não ser permitida a moderação de conteúdos por parte da IES. Outro ponto é a necessidade de pequenas alterações e adequações visuais solicitadas pela IES, que não seriam possíveis com a utilização do Facebook.

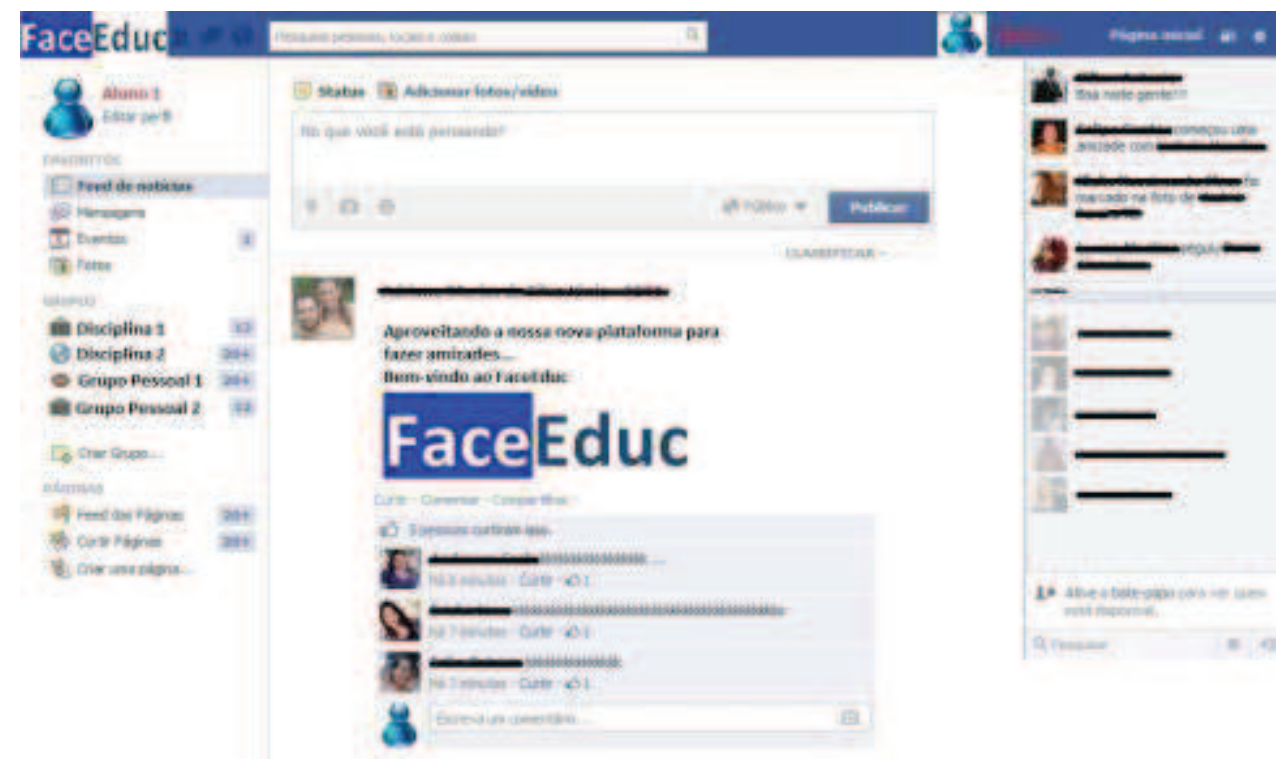

Figura 1. Interface Visual do FaceEduc

\subsection{Principais alterações e concepções visuais}

No FaceEduc, a criação de qualquer usuário, indiferente do papel que lhe seja atribuído, começa com a concepção de seu perfil, assim como no próprio Facebook, ou seja, todos os usuários tem um perfil próprio, podendo ou não alimentá-lo. Com o seu perfil criado, mesmo sem ter sido alocado em determinado papel, o usuário já pode interagir na área de rede social do ambiente (Figura 1).

Assim como no Facebook, o módulo de rede social permite a inclusão e alteração de foto do perfil e de capa, inserir link de vídeos, textos e fotos na linha do tempo, convidar amigos, adentrar e criar grupos públicos, utilizar o chat em grupo, curtir, compartilhar e comentar conteúdos, ou seja, todas as funções existentes na rede social Facebook, exceto a criação e execução de aplicativos e jogos.

Semelhante ao Facebook, o FaceEduc também incorpora as questões de segurança e permissão de acesso ao perfil do usuário, de forma que todas as ações tomadas no perfil possam ser controladas. Se a visualização e edição serão abertas apenas aos amigos, aos amigos de amigos ou ao público, é o usuário quem decide. Porém, indiferente do nível escolhido, o perfil de moderador conseguirá ler e editar qualquer conteúdo. No caso de edição, a ação é registrada em logs e informada via mensagem do próprio ambiente à pessoa que inseriu o conteúdo.

Outro ponto que tange à segurança é que, cada usuário, para criar o seu perfil, é obrigado a aceitar o termo de uso do FaceEduc, que contempla, entre outros assuntos, a ciência e aceitação à moderação dos conteúdos postados, os tipos de conteúdos considerados impróprios para o ambiente, informações sobre as responsabilidades pelas ações realizadas por cada usuário, podendo o mesmo sofrer as sanções administrativas, cíveis e criminais cabíveis. Tal ponto serviu para embasar a função do moderador assim 
como para instruir os usuários visto que, por ser semelhante ao Facebook, pressupunhase que as atitudes seriam semelhantes, ou seja, sem muita consciência de sua utilização conforme aponta Junior et al (2013).

Neste novo ambiente, assim como nas redes sociais, o círculo de amizade criado pode ser estendido a qualquer pessoa do ambiente, diferentemente da plataforma do Moodle, onde os alunos têm acesso apenas aos demais usuários cadastrados na mesma sala virtual. Outra funcionalidade do Facebook incorporada foi a concepção de eventos. No FaceEduc, os eventos apontam, assim como no Facebook, para os aniversários e eventos criados pelos usuários que contempla, como evento, todas as atividades dos alunos inerentes as disciplinas que o mesmo esteja participando. Ou seja, no calendário de eventos é possível estar ciente de todas as atividades, podendo estas serem filtradas por categoria: eventos pessoais, aniversários e atividades. Neste último caso existe a possibilidade de refinamento do filtro por disciplina, ou seja, mostra-se apenas as atividades específicas de um componente curricular.

Assim como no Facebook, todas as ações relativas ao perfil ou em que o perfil é citado é anunciada ao usuário através de símbolos na barra superior ao lado da logomarca da ferramenta (Figura 2). Quando o mesmo entra no sistema, é possível verificar as notificações, conforme Figura 2 (b), sendo que o primeiro símbolo representa ações relativas a convites de amizades, o segundo trata de conversas e chats e o terceiro de citações, curtidas ou compartilhamentos envolvendo o perfil. Após a leitura das notificações, os símbolos ficam esmaecidos, conforme Figura 2 (a), como meio de informar que não existem novidades ou pendências.

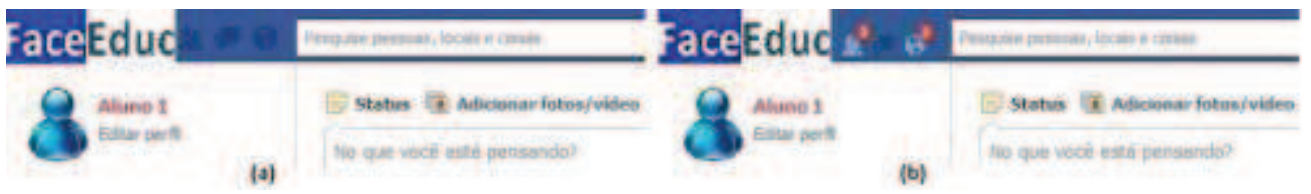

Figura 2. Interface Visual do FaceEduc

Todas as notificações citadas também podem ser enviadas por e-mail para o usuário, sendo ele capaz de configurar a ferramenta com as notificações que deseja receber por e-mail. Exceto o caso específico de notificação de evento de atividades, ou seja, as atividades das disciplinas. Neste caso, o usuário não tem como desabilitar a notificação e irá recebê-las por e-mail sete dias antes do evento, sendo repetida a notificação, caso o usuário ainda não a tenha executado, três vezes (quando faltar cinco dias, três dias e no dia do evento), além das notificações via ambiente.

\subsection{Os Papéis no ambiente do FaceEduc}

A plataforma Moodle utilizada no estudo conta com os papéis de alunos, tutores, professores, coordenadores, administrativos e técnicos (Figura 3). A função de aluno diz respeito aos próprios alunos, que têm permissão de alteração de dados pessoais, execução e visualização de atividades e conteúdos apenas das salas virtuais às quais estejam devidamente cadastrados.

Os tutores têm as mesmas permissões de visualização e edição dos alunos, mas acrescenta-se a possibilidade de geração de relatórios dos alunos, correção de atividades e postagem de notas. Já o perfil professor agrega todas as atividades dos tutores, além da possibilidade de criação e edição da própria sala de aula virtual. 
Os coordenadores acumulam todas as permissões já mencionadas dentro das disciplinas do curso que coordena e mais a possibilidade de inclusão e exclusão de usuários (alunos, tutores, professores ou administrativos) nas salas de aula virtuais.

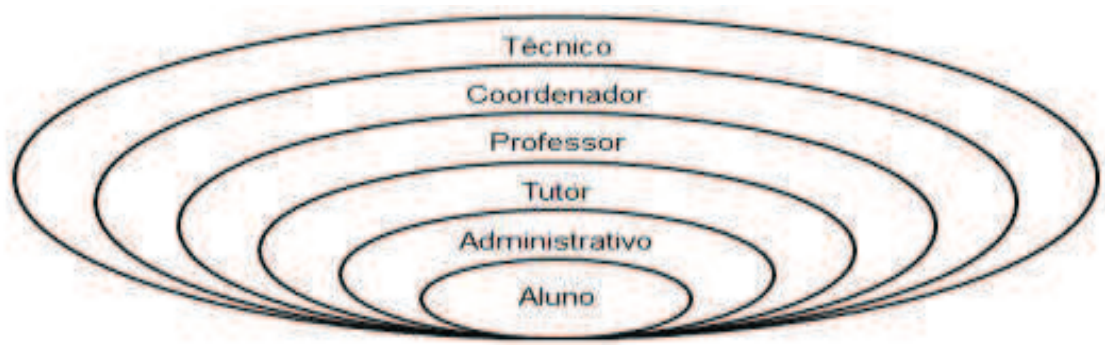

Figura 3. Papéis Migrados do Moodle para o FaceEduc

Complementando os papéis, têm-se os administrativos, perfil parecido ao de aluno, porém com capacidade de geração de relatório que contempla as funções de auditores educacionais, assessores pedagógicos, entre outros; e os técnicos, voltados para a equipe de suporte em informática que administra o ambiente computacional, possuem total acesso ao ambiente e suas configurações, inclusive de baixo nível (acesso físico à máquina hospedeira do ambiente).

Para a correta execução das atividades, todos os antigos papéis, supracitados, foram migrados na concepção do FaceEduc, acrescentando-se o papel de moderador de conteúdo, com acesso de edição aos conteúdos de todos os usuários, que tem como função principal o monitoramento dos conteúdos postados no FaceEduc, visto que cada usuário, em seu perfil e linha do tempo, pode postar vídeos, fotos e conteúdos diversos. Tais conteúdos devem então ser moderados de forma a não gerar problemas com conteúdos impróprios no novo ambiente educacional.

\subsection{Controle de conteúdos impróprios}

Ciente que o FaceEduc é uma rede social, a avalanche de dados inseridos trazem informações que não são percebidas facilmente, como coloca Malheiros e Lima (2013). Tal característica gerou problemas na concepção de um mediador para análise de conteúdos impróprios. A princípio, uma equipe de moderadores trabalharia na análise do conteúdo. Caso todo o conteúdo tivesse que ser analisado antes de ser liberado no ambiente, geraria um gargalo devido à grande quantidade de materiais lançados, assim como a necessidade de funcionamento do ambiente em tempo real. Por outro lado, apenas deixar os usuários cientes via termo de aceite na abertura da conta e após alguma denúncia ou detecção tomar as ações cabíveis ao detentor do perfil não era suficiente às concepções da instituição de ensino, visto que, mesmo tomando as ações contra o usuário, o conteúdo já teria sido postado no ambiente educacional, comprometendo o ambiente (por exemplo, por questões de malware) e a imagem da instituição (por exemplo, por conteúdos impróprios).

Para solucionar tal dilema, foi aplicada uma concepção de antispam, onde uma nova máquina virtual foi levantada com a ferramenta livre SpamAssassin ${ }^{13}$ e todas as mensagens eram analisadas automaticamente pela ferramenta (analisando conteúdo,

\footnotetext{
${ }^{13}$ SpamAssassin - http://spamassassin.apache.org/
} 
arquivos, imagens e códigos maliciosos), funcionando como um proxy entre o usuário e a ferramenta, conforme fluxo exposto na Figura 4.
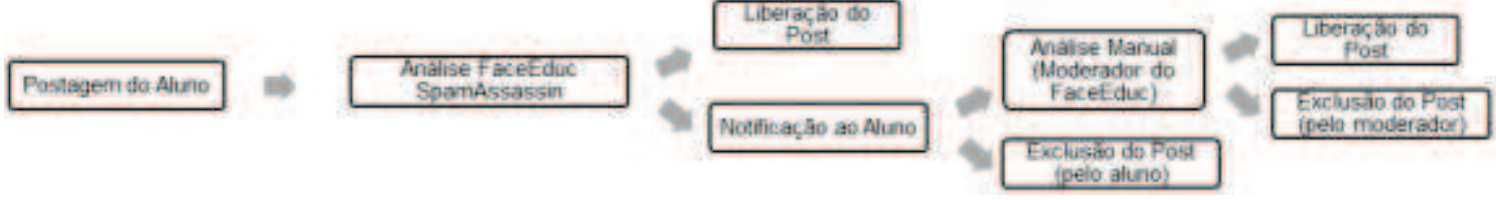

Figura 4. Proposta Final da Análise de Conteúdo no FaceEduc

No caso da ferramenta bloquear o conteúdo, o usuário recebe uma mensagem avisando que o arquivo ou mensagem foi detectado pela ferramenta de segurança e um link, onde o usuário tem a opção de excluir envio (neste caso o arquivo ou mensagem é descartada) ou esperar análise (neste caso o usuário moderador deverá analisar manualmente e permitir ou não o conteúdo). As postagens enviadas, analisadas e liberadas pela ferramenta (FaceEduc + SpamAssassin) eram postada no ambiente em tempo médio próximo a 2 segundos, não gerando problemas maiores de delay.

Após testes e ajustes finais para entrada em produção, os registros das ferramentas reportaram uma análise, após dois semestres letivos, de 1.957.027 mensagens. $\mathrm{O}$ que incorpora todo e qualquer conteúdo inserido por qualquer usuário do FaceEduc. Destas, 142.887 (7,3\%) foram detectadas pela ferramenta como conteúdo não apropriado. Sendo que em 21.037 situações (14,72\% do total detectado) foram solicitadas análise via moderador, o que resultou em $1.542(1,08 \%$ do total de mensagens detectadas) liberações manuais.

Para afinar o funcionamento da ferramenta, uma equipe de cinco analistas exercia o papel moderador, analisando as mensagens enviadas para verificação manual, assim como auditando as demais mensagens e perfis do ambiente por amostragem ou quando recebiam alguma denúncia. Tal ação reativa funcionava com complemento da análise proativa da ferramenta como forma de melhorar a segurança no ambiente e refinar a própria ferramenta. Nesta análise foram encontrados e retirados 31.127 conteúdos impróprios do ambiente, ou seja, conteúdo postado e que o SpamAssassin não detectou. Tal número representa $1,76 \%$ das mensagens que entraram no FaceEduc.

Acreditando que as mensagens bloqueadas e não solicitadas a análise via moderador, ou seja, excluída pelo usuário que a inseriu no ambiente eram realmente impróprias e que os analistas conseguiram analisar todo o ambiente, a ferramenta atendeu ao desejado, analisando em tempo hábil as mensagens e tendo 1,08\% de mensagens detectadas erroneamente (falso positivo) e 1,76\% de mensagens impróprias não detectadas (falso negativo). Tais números, apesar de serem considerados pela instituição excelentes resultados, ainda podem ser melhorados com atualizações da ferramenta e novos ajustes de configuração.

\subsection{Análises de Desempenho e Acadêmica}

Através do questionário utilizado, foi possível coletar informações sobre a aceitação e facilidade do uso do FaceEduc. O mesmo questionário foi enviado pelo ambiente para todos os alunos em 2013.1 (382 matriculados, sendo que 351 responderam ao questionário) e para todos os alunos de 2013.2 (793 matriculados, sendo que 701 responderam ao questionário). 
O primeiro ponto a se destacar é a aceitação dos discentes, pois, em 2013.1 93,45\% dos respondentes preferiram o FaceEduc ao ambiente tradicional. Em 2013.2 o índice encontrado para a preferência pela nova ferramenta foi de $95,15 \%$, analisando apenas os novos alunos de 2013.2 (411 discentes, sendo 364 respondentes), ou seja, excluindo aqueles que já estavam testando a ferramenta desde 2013.1, o índice foi de 93,13\%. Tais dados demonstram que, analisando apenas os alunos já inseridos em 2013.1, o índice, em 2013.2 foi de $97,33 \%{ }^{14}$, o que representa um aumento na preferência pelo FaceEduc após a sua utilização por dois semestres.

Com relação à facilidade de utilização do ambiente, $89,17 \%$ do grupo dos respondentes de 2013.1 e $86,54 \%$ dos inseridos em 2013.2 afirmaram não ter dificuldade na utilização do FaceEduc, mesmo sem treinamento específico algum, contra $91,88 \%$ em 2013.1 e 84,34\% dos alunos adicionados em 2013.2 para o ambiente tradicional. Entretanto, todos os alunos já utilizavam o ambiente tradicional da IES há mais de um semestre e tiveram uma capacitação inicial para uso do mesmo, fato que não ocorreu com o FaceEduc. Porém, salienta-se que 97,15\% dos respondentes de 2013.1 e 95,33\% dos inseridos em 2013.2 já possuíam perfil no Facebook, ou seja, 96,22\% da amostra total de respondentes, o que auxilia diretamente na adaptação ao FaceEduc.

Utilizando os dados da infraestrutura e logs do sistema, verificou-se um aumento do tempo online dos alunos (passando de 2 horas e 12 minutos por semana, no ambiente tradicional, para 5 horas e 7 minutos no FaceEduc em 2013.1 e 4 horas e 51 minutos em 2013.2), o que resultou em um aumento de 37\% em 2013.1 e 42\% em 2013.2 nas visualizações de atividades e materiais da disciplina inseridos no ambiente e um aumento de $21 \%$ em 2013.1 e $27 \%$ em 2013.2 na quantidade de atividades resolvidas, todos os percentuais comparam o semestre em questão com o ambiente tradicional.

Verificou-se também que o acesso ao ambiente tradicional no período de férias dos estudantes tende a zero. Já com o FaceEduc, 78,53\% dos alunos de 2013.1 e 80,83\% de 2013.2 entraram, ao menos, uma vez por semana, o que ocasionou em uma melhor comunicação para a matrícula dos alunos e reduziu em $17 \%$ a quantidade de matrículas no período estendido para alunos que perderam o prazo inicial do calendário acadêmico para o semestre de 2013.2, ou seja, os alunos do FaceEduc de 2013.1 e 14\% para a matrícula de 2014.1, ou seja, os alunos de 2013.2.

Em relação às notas, a média dos alunos participantes do projeto nas disciplinas que possuíam o suporte do FaceEduc, comparada com as demais do curso, tiveram um aumento de $12 \%$ em 2013.1 e $17,9 \%$ em 2013.2. Porém este acréscimo foi relativo apenas à execução de uma quantidade maior de atividades no ambiente e não por alguma alteração na formatação ou execução das atividades por parte do novo ambiente.

Quanto à infraestrutura concebida para o teste, verificou-se que no início de 2013.1 a utilização de espaço em disco aumentou 240\% e consumo do link de dados cresceu $87 \%$, grande parte devido aos uploads e downloads de arquivos, fotos e vídeos. Devido ao referido crescimento e visto que a infraestrutura da IES não comportaria esse acúmulo de utilização, o FaceEduc foi alterado de forma que não armazenasse as informações localmente nos servidores da IES. Para tanto, passaram a ser permitidos

\footnotetext{
${ }^{14} 337$ alunos dos 382 matriculados em 2013.1 que continuaram em 2013.2 responderam ao questionário.
} 
somente o envio de links de vídeos (grande parte oriundos do Youtube ${ }^{15}$ ) e no caso de upload de arquivos e fotos, estes deveriam ser armazenados em um serviço contratado na nuvem. Nesta nova topologia, tem-se um controle maior do crescimento da utilização da infraestrutura da IES (não apresentando alterações notáveis entre os dois ambientes). Porém, depende-se de terceiros, fato que, por ser imperceptível ao usuário, faz com que o mesmo acredite ser problema do FaceEduc quando, por exemplo, um vídeo que após ter sido excluído em sua origem externa não é executado no FaceEduc.

\section{Considerações Finais}

A inovação nos processos e metodologias pedagógicas aliadas aos desenvolvimentos tecnológicos impulsionam novos requisitos e aumentam as expectativas dos alunos. Os alunos já adotaram estilos de vida mais flexíveis, interativos e intemporais, servindo-se das tecnologias Web 2.0 para participar, partilhar e comunicar. As redes sociais são ambientes sociais e digitais, com conectividade e ubiquidade, baseadas na procura de aprendizagem, pelo que devemos ampliar a nossa visão pedagógica para que os alunos sejam participantes ativos e coprodutores de conteúdos, de modo que a aprendizagem seja um processo participativo, social, de apoio aos objetivos e necessidades individuais, porém sem se desprender dos princípios e orientações do modelo pedagógico da IES.

$\mathrm{Na}$ análise, percebe-se que os dados de dois semestres letivos deste estudo evidenciam que os alunos se adaptam melhor às tecnologias quando vão de encontro aos seus interesses e necessidades pessoais. Ou seja, a utilização prévia do FaceEduc como ambiente de aprendizagem contribuiu para que esse ambiente fosse gradualmente organizando-se como um espaço de integração, partilha, comunicação e colaboração entre todos, favorecendo e melhorando o desempenho dos discentes. Assim como, possibilita a redução de custo para a IES, visto que não se fez mais necessário um treinamento inicial (ou pode ser diminuído) para adaptação ao AVA.

\section{Referências}

Alencar, G. D. et al (2013). FaceEduc: Uma Adaptação Visual do Moodle Baseada na Interface e Mecanismos de Interação do Facebook. In: XXIV Simpósio Brasileiro de Informática na Educação (SBIE). Campinas, SP.

Alexa. (2013). "The web Information Company", http://www.alexa.com/ siteinfo/facebook.com, Acesso em: 17 jul. 2013.

Araújo, A. M.; Cavalcanti, A. C.; Dos Anjos, L. (2006). Estudo comparativo sobre plataformas de EaD baseadas em software livre. In: XVII Simpósio Brasileiro de Informática na Educação (SBIE). Brasília, DF.

Braz, L. M. (2013). Uma Arquitetura Flexível para Promover a Integração entre o Moodle e Sites de Redes Sociais. Revista Brasileira de Informática na Educação (RBIE), v. 21, n. 1, p.37-51.

Castells, M. (2007) Era da Informação: A Sociedade em Rede. Volume 1. 10a Edição. São Paulo: Editora Paz e Terra, 698 p.

\footnotetext{
${ }^{15}$ Youtube - http://www.youtube.com
} 
Cosenza, V. (2012) "World Map of Social Networks, according to Alexa \& Google Trends for Websites traffic data", http://vincos.it/world-map-of-social-networks, Acesso em: 02 ago. 2013.

Costa, R. (2005). On a New Community Concept: Social Networks, Personal Communities, Collective Intelligence. In: Interface - Comunic., Saúde, Educ. v.9, n.17, p.235-48, mar/ago.

Ellison, N. B.; Steinfield, C.; Lampe, C. (2007). The Benefits of Facebook "Friends": Social Capital and College Students' Use of Online Social Network Sites. In: Journal of Computer-Mediated Communication, 12(4), p. 1143-1168.

Facebook. (2014) "Facebook Brasil", https://www.facebook.com/FacebookBrasil/info, Acesso em: 10 jan. 2014.

IBOPE Nielsen Online. (2012). "Internet no Brasil cresceu 16\% em um ano". http://www.abradi.com.br/noticias/ibope-nielsen-online-internet-no-brasil-cresceu16-em-um-ano/. Acesso em: 08 jan. 2014.

Junior, M. P. et al. (2013). O Navegar Impreciso - A Privacidade no Facebook Vivenciada por seus Usuários. In: IX Simpósio Brasileiro de Sistemas de Informação (SBSI). João Pessoa, PB.

Lima, V. G. et al (2012). UbibusRoute: Um Sistema de Identificação e Sugestão de Rotas de Ônibus Baseado em Informações de Redes Sociais. In: VIII Simpósio Brasileiro de Sistemas de Informação (SBSI). São Paulo, SP.

Malheiros, Y.; Lima, G. (2013). Uma Ferramenta para Análise de Sentimentos em Redes Sociais Utilizando o SenticNet. In: IX Simpósio Brasileiro de Sistemas de Informação (SBSI). João Pessoa, PB.

Marcon, K.; Machado, J. B.; Carvalho, M. J. S. (2012). Arquiteturas Pedagógicas e Redes Sociais: Uma experiência no Facebook. In: XXIII Simpósio Brasileiro de Informática na Educação (SBIE). Rio de Janeiro, RJ.

Mendes, E.; Carvalho, H., Brito, M. A. (2012). A influência do Facebook nas vendas: a percepção dos consumidores de moda. In: Congresso Internacional de Moda e Design, Guimarães, Portugal.

Oliveira, J. P.; et al. (2010). ProEdu : Integrando a Rede Social Social Orkut ao Moodle. In: XXI Simpósio Brasileiro de Informática na Educação (SBIE). João Pessoa, PB.

Royal Pingdom. (2013) "Internet 2012 in numbers", http://royal.pingdom.com/2013/01/ 16/internet-2012-in-numbers/, Acesso em: 02 jan. 2014.

Social Bakers. (2013). "Brazil Facebook Statistics", http://www.socialbakers.com/ facebook-statistics/brazil, Acesso em: 25 Out. 2013. 